\title{
Multimorbidity in family medicine clerkship
}

\section{The student perspective}

\author{
Emily Harrison (Meds 2015)
}

Faculty Reviewers: Dr William E Osmun, MD, CCFP (Department of Family Medicine), Dr George Kim, MD, CCFP (Department of Family Medicine)

\section{ABSTRACT}

PURPOSE: To document senior medical students' experiences in caring for patients with multiple chronic illnesses in family medicine clerkship and explore their attitudes towards the inclusion of this topic in existing curricula.

METHODS: A cohort of third-year medical students from the Schulich School of Medicine and Dentistry at the University of Western Ontario were surveyed following their core family medicine clerkship.

RESULTS: One hundred percent of students surveyed participated in the care of patients with multiple chronic illnesses during their family medicine clerkship. However, only $28 \%$ percent reported receiving formal teaching on this topic while $\mathbf{8 9 . 5 \%}$ felt that multimorbidity should be taught at the clerkship level. The majority of students surveyed felt comfortable caring for this patient population.

CONCLUSION: Patients with multiple chronic illnesses are common in family practice. All third-year medical students encountered patients with multimorbidity during their family medicine clerkship. This study contributes to a growing body of literature that suggests the need for a shift in medical education and health care delivery in order to better serve an increasingly complex patient population.

\section{INTRODUCTION}

Canadian medical undergraduate trainees enter clerkship in either their second or third year and for many this is their first exposure to clinical practice. Primary care educators are challenged with introducing medical students to the broad range of topics present in family medicine. ${ }^{1}$ The Canadian Undergraduate Family Medicine Education Directors have published the Canadian Shared Family Medicine Clerkship Curriculum in an effort to provide learners with resources to supplement their clerkship experiences. ${ }^{2}$ This learning tool provides objectives, reference cards and cases for 23 common presentations in family practice. However, there is no information relating to the management of patients with multiple chronic illnesses. Multimorbidity is defined as the presence of two or more chronic medical conditions within one individual. ${ }^{3}$ The prevalence of such patients is increasing, and family physicians play an important role in their medical care. ${ }^{3-8}$ Numerous studies have shown that patients with multiple morbidities experience a decreased quality of life, worse health care outcomes and lower level of functional status. ${ }^{4-8}$ It is important that medical trainees are appropriately trained to care for an increasingly complex patient population. Medical education and treatment guidelines are based on a single-disease model and provide little guidance for the management of multiple chronic illnesses within one patient. ${ }^{3,6,9,10}$ Our previous work has shown that medical undergraduate educators agree that clinical clerks should be exposed to the management of multiple chronic illnesses in family medicine training; however, the majority of existing curricula do not address this topic. ${ }^{11}$

The purpose of this study was to document medical students' experiences caring for patients with multiple morbidities and explore their perspectives on the teaching of multimorbidity in family medicine clerkship.

\section{METHODS}

A 12-item, paper-based survey was developed aimed at documenting students' experiences caring for patients with multiple chronic illnesses during their core family medicine rotation. Primary survey items explored students' attitudes towards receiving formal teaching on patients with multiple morbidities at the clerkship level. Participants were given the opportunity to provide further comments on their experiences caring for patients with multiple chronic illnesses as well as feedback on the survey in an open-ended question. Formal teaching was defined as structured learning that takes place in the following formats: lectures, resident

Table 1: Format of multimorbidity teaching in family medicine clerkship, choose all that apply $(n=13)$

\begin{tabular}{lcc}
\hline Answer options & Response percent & Response count \\
\hline Lectures/rounds & $38.5 \%$ & 5 \\
\hline Topic presentations & $15.4 \%$ & 2 \\
\hline Small-group discussions & $30.8 \%$ & 4 \\
\hline Assigned readings & $30.8 \%$ & 4 \\
\hline Online case modules & $0.0 \%$ & 0 \\
\hline OsCE & $0.0 \%$ & 10 \\
\hline Resident teaching & $76.9 \%$ & 5 \\
\hline Other (please specify) & $38.5 \%$ & 0 \\
\hline
\end{tabular}

Table 2: Do you feel that you have a practical approach to the management of patients with multiple morbidities in family practice? $(n=56)$

\begin{tabular}{lcc}
\hline Answer options & Response percent & Response count \\
\hline Yes & $55.4 \%$ & 31 \\
\hline No & $17.9 \%$ & 10 \\
\hline Unsure & $26.8 \%$ & 15 \\
\hline
\end{tabular}


ORIGINAL ARTICLE

Table 3: On a scale of 1-10, how comfortable are you with the management of patients with multiple chronic illnesses? $(\mathrm{n}=57)$

\begin{tabular}{|c|c|c|c|c|c|c|c|c|c|c|c|c|}
\hline Answer options & 1 & 2 & 3 & 4 & 5 & 6 & 7 & 8 & 9 & 10 & Rating average & Standard deviation \\
\hline Response Count & 0 & 0 & 1 & 2 & 10 & 10 & 21 & 9 & 4 & 0 & 6.60 & 1.30 \\
\hline
\end{tabular}

Table 4: Do you think that third year clinical clerks should be taught an approach to the management of patients with multiple morbidities during the family medicine rotation? $(n=57)$

\begin{tabular}{lcc}
\hline Answer options & Response percent & Response count \\
\hline Yes & $89.5 \%$ & 51 \\
\hline No & $1.8 \%$ & 1 \\
\hline Unsure & $8.8 \%$ & 5 \\
\hline
\end{tabular}

Table 5: If you have any further comments regarding multimorbidity in your family medicine rotation, please include them below $(n=6)$

It's difficult to have an approach to multiple morbidities early on and I think it is something that comes with more clinical experience.

Seems very vague; not every patient will be the same. How extensive is the teaching going to be? Not sure if it's necessary.

Geriatrics during internal was the only place we really saw multimorbidity discussed - it was great, but a bit more would be nice.

IM had formal teaching in multimorbidity in the context of geriatrics.

Multimorbidity is the rule in family. We didn't learn a pocket approach.

Haven't done surgery yet so can't comment.

teaching, online modules and assigned readings. Students received surveys following the final assessment of their core family medicine rotation and completed surveys were entered into an electronic database for analysis. Third-year medical students who had completed their family medicine rotation at the Schulich School of Medicine and Dentistry between April 2014 and September 2014 were eligible to participate. Ethics approval was obtained from the University of Western Ontario's Research and Ethics Board.

\section{RESULTS}

Paper surveys were distributed to a total of 63 students and 57 were returned, giving a response rate of $90 \%$. All participants were part of the 2015 class at Western University. Of these, $81 \%$ of respondents completed their family medicine clerkship in a rural setting, while $100 \%$ of respondents indicated that multimorbidity was common in family practice and $100 \%$ were involved in the care of patients with multiple chronic illnesses during their family medicine clerkship. However, only $28.1 \%$ received formal teaching on the management of such patients. Those who did receive formal teaching were asked to list the formats utilized by their preceptors during the core family medicine rotation (Table 1). However, of those who did not receive formal teaching on multimorbidity, $81 \%$ indicated that their preceptors discussed the management of patients with multiple chronic illnesses. Respondents were asked to indicate if they felt they had a practical approach to patients with multiple chronic illnesses (Table 2). Respondents were also asked to indicate on a 10-point Likert scale whether they felt comfortable caring for patients with multiple morbidities, 10 indicating a high level of comfort and 1 indicating a low level of comfort (Table
3). The average response was $6.60(\mathrm{SD}=1.30)$. Respondents were asked to indicate whether multimorbidity should be included in formal teaching during the family medicine rotation (Table 4) and if they had received formal teaching on this topic in any other core rotation during their clerkship training. Internal medicine was the most common (48/50), followed by psychiatry (17/50) and surgery (10/50). Respondents were given the opportunity to provide any further comments about their experiences with multimorbidity in family medicine clerkship (Table 5).

\section{DISCUSSION}

All students surveyed were involved in the care of patients with multiple chronic illnesses during their family medicine rotation and the vast majority felt that third-year clinical clerks could benefit from formal teaching on multimorbidity. These findings further support the literature indicating that patients with multiple chronic illnesses are increasingly common in family practice and that medical education fails to address the needs of this patient population..$^{3-8,10-11}$ Respondents indicated that they received formal teaching on multimorbidity in other clinical areas, internal medicine (48/50) being the most common. Interestingly, more than half of respondents indicated that they felt comfortable caring for patients with multiple chronic illnesses in a primary care setting, despite the paucity of formal teaching on this topic within the family medicine curriculum. It was surprising that the majority of students surveyed indicated a relatively high level of comfort in caring for such a complex patient population. However, literature on undergraduate education suggests medical students' ability to accurately assess their own performance and knowledge base is highly variable and often inaccurate. ${ }^{12-14}$ Future studies could focus on senior medical students' ability to self-assess their proficiency in caring for patients with multimorbidity.

The responses to the open-ended survey item, while few in number, suggest the need for further study on students' experiences caring for patients with multiple chronic illnesses. Focus groups with senior medical students could provide a more complete view of their experiences in family medicine clerkship and could be useful in the development of learning tools to aid in the care of patients with multimorbidity.

This study is not without limitations; our survey instrument was not previously validated, and respondents commented during the survey session that some items were unclear. We surveyed a cohort of third-year students exclusively from Western University and therefore our findings may not be representative of the experience of undergraduate trainees at other institutions.

Despite these limitations, this study speaks to the need for further development in family medicine undergraduate education beyond the single-disease model.

\section{ACKNOWLEDGMENTS}

Special thanks to Dr Ted Osmun, Dr George Kim and Leslie Boisvert for their support and guidance. 


\section{REFERENCES}

1. Steyer TE. What should our students learn: the family medicine clerkship curricular guidelines. Fam Med. 2010 Jan;42(1):12-3.

2. SHARC-FM. Canada: The College of Family Physicians of Canada. [cited 2015 Apr 16]. Available from: https://sites.google.com/site/ sharcfm/welcome.

3. Fortin M, Lapointe L, Hudon C, Vanasse A, Ntetu AL, Maltais D. Multimorbidity and quality of life in primary care: a systematic review. Health Qual Life Outcomes 2004;2:51.

4. Barnett K, Mercer SW, Norbury M, Watt G, Wyke S, Guthrie B. Epidemiology of multimorbidity and implications for health care, research, and medical education: a cross-sectional study. Lancet. $2012 \mathrm{Jul}$ 7;380(9836):37-43

5. Stewart AL, Greenfield S, Hays RD, Wells K, Rogers WH, Berry SD, McGlynn EA, Ware JE Jr. Functional status and well-being of patients with chronic conditions. Results from the Medical Outcomes Study. JAMA. 1989 Aug 18;262(7):907-13.

6. St John PD, Tyas SL, Menec V, Tate R. Multimorbidity, disability, and mortality in community-dwelling older adults. Can Fam Physician. 2014 May;60(5):e272-80.

7. Fortin M, Bravo G, Hudon C, Vanasse A, Lapointe L. Prevalence of multimorbidity among adults seen in family practice. Ann Fam Med. 2005 May-Jun;3(3):223-8.

8. Fortin M, Bravo G, Hudon C, Lapointe L, Almirall J, Dubois MF, Vanasse A. Relationship between multimorbidity and health-related quality of life of patients in primary care. Qual Life Res. 2006 Feb;15(1):83-91.

9. Yardley S, Cottrell E, Protheroe J. Understanding success and failure in multimorbidity: protocol for using realist synthesis to identify how social learning and workplace practices can be optimised. Syst Rev. 2013 Sep 25;2:87.

10. Rushton CA, Green J, Jaarsma T, Walsh P, Strömberg A, Kadam UT. The challenge of multimorbidity in nurse education: an international perspective. Nurse Educ Today. 2015 Jan;35(1):288-92.

11. Harrison E, Osmun T, Kim G, Boisvert L. Multimorbidity in Canadian Family Medicine Education. Poster presented at: 2014 Canadian Conference Medical Education.

12. Blanch-Hartigan D. Medical students' self-assessment of performance: results from three meta-analyses. Patient Educ Couns. 2011 Jul;84(1):3-

13. Langendyk V. Not knowing that they do not know: self-assessment accuracy of third-year medical students. Med Educ. 2006 Feb;40(2):1739.

14. Tousignant M, DesMarchais JE. Accuracy of student self-assessment ability compared to their own performance in a problem-based learning medical program: a correlation study. Adv Health Sci Educ Theory Pract. 2002;7(1):19-27

\section{Less time at the bank. More time with your patients.}

BMO Harris Private Banking provides you with one dedicated relationship manager that understands the unique needs of physicians.

Visit bmo.com/physicians or call 1-855-666-4360.

BMO Harris Private Banking。

"BMO (M-bar roundel symbol) Harris Private Banking" is a registered trade-mark of Bank of Montreal, used under licence. 